\title{
Changes in pulmonary function tests in breast carcinoma patients treated with locoregional post-mastectomy radiotherapy: results of a pilot study
}

\author{
This article was published in the following Dove Press journal: \\ Breast Cancer - Targets and Therapy \\ 29 May 2017 \\ Number of times this article has been viewed
}

\section{Eyad Fawzi AlSaeed' \\ Faisal Khalid Balaraj ${ }^{2}$ \\ Mutahir A Tunio ${ }^{3}$ \\ 'Department of Radiation Oncology, Faculty of Medicine, King Saud University, King Khalid University Hospital, Riyadh, Saudi Arabia; ${ }^{2} \mathrm{Al}$ Faisal University, Chair of Radiation Oncology, Tawam Hospital, Al Ain, United Arab Emirates; ${ }^{3}$ Radiation Oncology, Comprehensive Cancer Center, King Fahad Medical City, Riyadh, Saudi Arabia}

Background: The aim of present pilot study was to evaluate the changes in pulmonary function tests (PFTs) after locoregional post-mastectomy radiotherapy (PMRT) in breast cancer patients. Materials and methods: Twenty consecutive patients with histopathologically confirmed breast carcinoma stages T1-T4, N1-N2, who were treated with modified radical mastectomy with neoadjuvant or adjuvant chemotherapy underwent PFTs, including forced vital capacity (FVC), forced expiratory volume in 1 second $\left(\mathrm{FEV}_{1}\right)$, forced expiratory flow at $50 \%$, and peak expiratory flow rate, maximum mid expiratory flow $\left(\mathrm{MMEF}_{25-75}\right)$, maximal oxygen consumption $\left(\mathrm{VO}_{2} \mathrm{max}\right)$, and carbon monoxide diffusing capacity (DLCO) before, at 30 days, and at 90 days after locoregional PMRT. A two-tailed paired Student's $t$-test was used to compare mean values among the variables between the groups

Results: A significant drop in FVC, $\mathrm{FEV}_{1}$, and DLCO was noticed at day 90 after the completion of locoregional PMRT with $P$-values $0.033,0.042$, and 0.031 , respectively, while $\mathrm{MMEF}_{25-75}$ and $\mathrm{VO}_{2}$ max were not significantly affected ( $P$-values 0.075 and 0.062 , respectively) favoring a restrictive lung injury pattern. However, no patient was found to be symptomatic.

Conclusion: A significant drop in reduction in PFTs occurred at day 90 after the completion of locoregional PMRT. PFTs shall be performed in all breast cancer patients receiving locoregional PMRT for early detection of radiation-induced lung toxicity as all patients in our cohort were found asymptomatic.

Keywords: breast carcinoma, locoregional, post-mastectomy radiotherapy, changes in pulmonary function tests

\section{Introduction}

During the post-mastectomy radiotherapy (PMRT) with tangential fields, usually a small portion of the underlying lung is included within the radiation portals, which may result in potential risk of radiation-induced lung toxicity (RILT). ${ }^{1}$ RILT is typically manifested clinically either as acute radiation-induced pneumonitis (RIP), or late radiation-induced fibrosis (RIF). ${ }^{2,3}$ RIP usually occurs 4-12 weeks after the completion of PMRT and in most of the patients it is often indolent, although in few it can present as cough and shortness of breath. In most of cases, RIP is regressed spontaneously or with use of steroids; however, it can also evolve into RIF as consequential late toxicity. ${ }^{4,5}$ RIP and RIF are mainly related to 1) the volume of irradiated lung parenchyma, 2) mean lung dose, 3) fractionation schedule, and 4) concurrent chemotherapy ${ }^{6,7}$ However, pulmonary functional reserve is not only limited by previously mentioned factors, but also affected
Correspondence: Mutahir A Tunio Radiation Oncology, Comprehensive Cancer Center, King Fahad Medical City, P O Box 59046, Riyadh, Saudi Arabia Tel +966 II I 2889999

Email mkhairuddin@kfmc.med.sa 
by 1) involvement or not of supraclavicular (SC) region, ${ }^{8} 2$ ) radiotherapy techniques, ${ }^{9} 3$ ) smoking habits, ${ }^{10}$ and 4) the use of concurrent tamoxifen. ${ }^{11}$ Although RILT may not increase the risk of death, it has a negative impact on quality of life, and breast carcinoma patients with compromised pulmonary functional reserve may have relatively inferior long-term treatment outcomes. ${ }^{3,8}$ There is limited data available regarding the changes in pulmonary function tests (PFTs) in breast carcinoma patients receiving PMRT. Few studies have documented a significant decrement in PFTs in breast carcinoma patients who were treated with PMRT including SC region and were given adjuvant chemotherapy. 3,9,12

In the present study, we aimed to evaluate the acute changes in PFTs in breast carcinoma patients who received adjuvant chemotherapy and were treated with PMRT including SC regions.

\section{Materials and methods Eligibility}

The study was approved by the Ethics Committee of King Saud University. All participants provided written informed consent to participate in this study. There were, 20 consecutive eligible women presenting with breast carcinoma enrolled in this study, and were treated with PMRT (chest wall, SC region \pm axilla) after modified radical mastectomy (MRM). Inclusion criteria were 1) patients with histopathological confirmed breast carcinoma, 2) patients with T1-T4, N1-N2, and 3) patients who underwent MRM with neoadjuvant or adjuvant chemotherapy.

Exclusion criteria were 1) patients with N0 status and were not candidates for SC region PMRT, 2) patients with N3 status or in whom radiotherapy to internal mammary lymph node was given, 3) patients who did not receive neoadjuvant/adjuvant chemotherapy, 4) presence of distant metastasis, 5) history of bronchial asthma and chronic obstructive pulmonary disease, 6) history of smoking, and 7) any contraindications for spirometry (unstable angina, history of myocardial infarction, or comprised cardiac functions, aorta aneurysm, cerebral aneurysms, and syncope associated with forced exhalation).

\section{Radiotherapy techniques}

All patients underwent computed tomography (CT) simulation in supine position on breast board with head turned to contralateral side of region of interest (ROI), with both arms placed above the head. CT data were obtained with a highspeed 16-slice helical scanner at $5 \mathrm{~mm}$ slices through the ROI. A single isocenter was marked at the level of match line between the SC and breast below the medial end of clavicle. After the acquisition of CT data, clinical target volume (CTV) including chest wall, SC region, and level III axillary lymph node region was delineated. Organs at risk (OAR) including spinal cord, heart, and both lungs were also delineated on each CT slice. For all patients, three-dimensional conformal radiotherapy plans were created using Eclipse ${ }^{\mathrm{TM}}$ (Varian Medical Systems, Inc., Palo Alto, CA, USA) version 10.0. Opposed tangential fields were designed to encompass the contoured CTV chest wall. Superior border of the CTV chest wall field was defined by the inferior extent of the SC area, which corresponded to the single isocenter. The inferior edge was placed at $2 \mathrm{~cm}$ below the level of infra-mammary fold of contralateral breast. The angle of tangential fields was opted to avoid too much lung volume in tangential fields. Dynamic wedges were used to maintain homogeneity within $\pm 10 \%$. A single antero-posterior field was matched to the superior border of the CTV chest wall tangential fields to encompass the $\mathrm{SC}$ region (Figure 1). A gantry angle of $5^{\circ}-15^{\circ}$ was applied to minimize the spinal cord dose. Wedges were used to create homogeneity in each plan. A dose of $50 \mathrm{~Gy}$ in 25 fractions ( $2 \mathrm{~Gy} /$ fraction/day) was prescribed to the chest wall, SC, and level III axillary nodes. A dose-volume histogram (DVH)
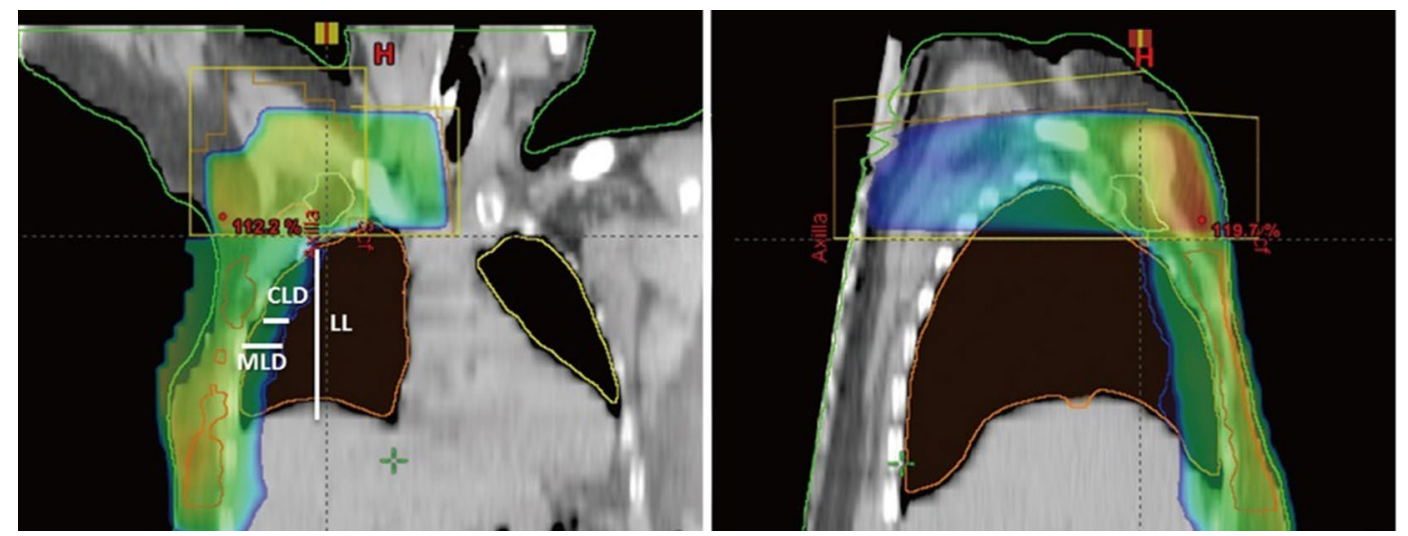

Figure I Treatment plans showing beam design and dose distributions for supraclavicular and tangential fields.

Notes: Sagittal view of supraclavicular and chest wall radiation portals (left); coronal view of supraclavicular and chest wall radiation portals (right).

Abbreviations: LL, left lung; CLD, central lung distance; MLD, mean lung distance. 
was created to check the CTV dose coverage and the dose to each OAR. Treatment planning directed at good coverage of the CTV chest wall and SC and respected the International Commission on Reporting Units algorithms.

\section{Pulmonary function tests}

The study employed the ndd EasyOne Pro ${ }^{\circledR}$ Spirometry Lab system. This system was used to acquire baseline PFTs before the commencement of radiotherapy, consisting of forced vital capacity $(\mathrm{FVC})$, forced expiratory volume in 1 second $\left(\mathrm{FEV}_{1}\right)$, maximum mid expiratory flow $\left(\mathrm{MMEF}_{25-75}\right)$, maximal oxygen consumption $\left(\mathrm{VO}_{2} \max \right)$, and carbon monoxide diffusing capacity (DLCO). These measurements were repeated after 30 and 90 days after completion of radiotherapy. FVC was considered as surrogate for lung volume, while $\mathrm{FEV}_{1}$ was considered a surrogate for the narrowing of large or mediumsized bronchi. $\mathrm{MMEF}_{25-75}$ was regarded as a surrogate for the narrowing of bronchioles; $\mathrm{VO}_{2}$ max was defined as the oxygen uptake attained during maximal exercise intensity that could not be increased despite further increases in exercise workload, and DLCO was used as surrogate for the diffusing capacity through the alveolar-capillary barrier. Additionally, $\mathrm{FEV}_{1} \%$ pred $\left(\mathrm{FEV}_{1} / \mathrm{FVC}\right)$, forced expiratory flow at $50 \%$ when $50 \%$ of the FVC has been exhaled, and peak expiratory flow rate (PEFR) to assess expiratory muscle strength and large airway patency were noted down. Theoretically, FVC, FEV , and DLCO are reduced in RIP, and all of aforementioned parameters are reduced in RIP and lung fibrosis.

\section{DVH data}

For the purpose of study, DVH to lungs and volume percentages of the ipsilateral lung absorbing 5, 10, 20, 30, 40, and 50 Gy (V5, V10, V20, V30, V40, and V50), respectively, were estimated. The continuous variables were dichotomized at respective median values.

\section{Statistical analysis}

Statistical Package for Social Science version 24.0 (IBM Corp., Armonk, NY, USA) was used for data analysis. Mean, minimum, maximum, and standard deviation were calculated for quantitative data description. A two-tailed paired Student's $t$-test was subsequently used to compare mean values among the variables between the groups. A $P$-value of 0.05 was considered statistically significant.

\section{Results}

Median age of cohort was 44.95 years (range: 25-68). Three patients $(15 \%)$ were known to have comorbidities (hypertension and diabetes). Majority of the cohort (17 patients; $85 \%$ ) had left-side breast cancer. Majority of the cohort (85\%) also had advanced primary (T3 and T4 stages) and N2 status (65\%). Other histopathological features, receptor status, chemotherapy, and radiotherapy doses in the study population are shown in Table 1. Neoadjuvant and adjuvant chemotherapy regimen in the cohort was three cycles of 5 -fluorouracil $600 \mathrm{mg} / \mathrm{m}^{2}$, epirubicin $60 \mathrm{mg} / \mathrm{m}^{2}$, and cyclophosphamide $600 \mathrm{mg} / \mathrm{m}^{2}$ every 3 weeks followed by three cycles of docetaxel $75 \mathrm{mg} / \mathrm{m}^{2}$. In all, 5/20 (25\%) patients were given trastuzumab during and after radiation therapy.

\section{Pulmonary function tests}

Comparative analysis of different baseline PTFs parameters and those obtained at days 30 and 90 after the completion of radiotherapy are presented in Table 2 . A significant decrease

Table I Patients' baseline characteristics

\begin{tabular}{|c|c|}
\hline Variables & Number (\%) \\
\hline Age (years) mean & 44.95 (25-68); SD I I.85 \\
\hline \multicolumn{2}{|l|}{ Menopausal status } \\
\hline Pre-menopausal & $14(70.0)$ \\
\hline Post-menopausal & $6(30.0)$ \\
\hline \multicolumn{2}{|l|}{ Comorbidities } \\
\hline Hypertension & I (5.0) \\
\hline Diabetes & $2(10.0)$ \\
\hline \multicolumn{2}{|l|}{ Side } \\
\hline Right & $3(15.0)$ \\
\hline Left & $17(85.0)$ \\
\hline \multicolumn{2}{|l|}{ T stage } \\
\hline \multicolumn{2}{|l|}{$\mathrm{TI}$} \\
\hline $\mathrm{T} 2$ & $3(15.0)$ \\
\hline T3 & $16(80.0)$ \\
\hline $\mathrm{T} 4$ & I (5.0) \\
\hline \multicolumn{2}{|l|}{$\mathrm{N}$ status } \\
\hline NI & $7(35.0)$ \\
\hline N2 & $13(65.0)$ \\
\hline \multicolumn{2}{|l|}{ Histopathological type } \\
\hline IDC & $19(95.0)$ \\
\hline ILC & I $(5.0)$ \\
\hline \multicolumn{2}{|l|}{ LVSI } \\
\hline Yes & $8(40.0)$ \\
\hline No & $12(60.0)$ \\
\hline \multicolumn{2}{|l|}{ Receptor status } \\
\hline $\mathrm{ER}+/ \mathrm{PR}+/ \mathrm{Her} 2$ neu- & $3(15.0)$ \\
\hline $\mathrm{ER}+/ \mathrm{PR}+/ \mathrm{Her} 2$ neu+ & $5(25.0)$ \\
\hline ER+/PR-/Her 2 neu- & $6(30.0)$ \\
\hline ER-/PR-/Her 2 neu- & $4(20.0)$ \\
\hline ER-/PR+/Her 2 neu- & $2(10.0)$ \\
\hline \multicolumn{2}{|l|}{ Chemotherapy } \\
\hline Neoadjuvant & $17(35.0)$ \\
\hline Adjuvant & $3(65.0)$ \\
\hline Radiotherapy dose (mean) & 50 Gy (50-66 Gy) \\
\hline
\end{tabular}

Abbreviations: SD, standard deviation; T, tumor; N, node; IDC, infiltrating ductal carcinoma; ILC, infiltrating lobular carcinoma; LVSI, lymphovascular invasion; ER, estrogen receptor; PR, progesterone receptor. 
Table 2 Pulmonary function tests performed before, at day 30, and at day 90 after radiotherapy

\begin{tabular}{lllll}
\hline Parameters & Baseline Mean (range) & Day 30 Mean (range) & Day 90 Mean (range) & P-value \\
\hline FVC $(\mathrm{L})$ & $2.94(2.74-3.1 \mathrm{l})$ & $2.94(2.70-3.10)$ & $2.68(2.42-2.92)$ & $\mathbf{0 . 0 3 3}$ \\
$\mathrm{FEV}_{1}(\mathrm{~L} / \mathrm{s})$ & $2.52(2.43-2.68)$ & $2.12(2.04-2.64)$ & $2.30(2.15-2.52)$ & $\mathbf{0 . 0 4 2}$ \\
$\mathrm{FEV}_{1} \%$ pred $(\mathrm{FEV}, / \mathrm{FVC})$ & $85.7(77.8-99.8)$ & $83.7(75-99.8)$ & $84.5(75.3-90.8)$ & 0.053 \\
$\mathrm{MMEF}_{25-75}(\mathrm{~L} / \mathrm{s})$ & $3.36(3.18-3.53)$ & $3.35(3.16-3.52)$ & $3.32(3.15-3.49)$ & 0.075 \\
$\mathrm{VO}_{2} \mathrm{max}(\mathrm{L} / \mathrm{min})$ & $1.84(1.69-2.09)$ & $1.72(1.67-1.77)$ & $1.70(1.65-1.74)$ & 0.062 \\
$\mathrm{DLCO}_{(\mathrm{mmol} / \mathrm{kPa} / \mathrm{min})}$ & $8.04(7.72-8.36)$ & $7.95(7.58-8.31)$ & $7.81(7.50-8.18)$ & $\mathbf{0 . 0 3 1}$ \\
$\mathrm{FEF}_{50}(\mathrm{~L} / \mathrm{s})$ & $4.04(3.79-4.36)$ & $3.90(3.73-4.34)$ & $3.98(3.78-4.02)$ & 0.054 \\
PEFR $(\%)$ & $94.5(83.9-104.8)$ & $92.9(81.85-103.37)$ & $93.6(83.15-101.47)$ & 0.083 \\
\hline
\end{tabular}

Notes: Bold figures represent $P<0.05$.

Abbreviations: $\mathrm{FVC}$, forced vital capacity; $\mathrm{FEV}_{1}$, forced expiratory volume in I second; $\mathrm{MMEF}_{25-75}$, maximum mid expiratory flow; $\mathrm{VO}_{2}$ max, maximum oxygen consumption; $\mathrm{DLCO}$, carbon monoxide diffusing capacity; $\mathrm{FEF}_{50}$, forced expiratory flow at $50 \%$; PEFR, peak expiratory flow rate.

of FVC, $\mathrm{FEV}_{1}$, and DLCO was noticed at day 90 after the completion of radiotherapy with $P$-values $0.033,0.042$, and 0.031 , respectively (Figures 2-4), while $\mathrm{MMEF}_{25-75}$ and $\mathrm{VO}_{2}$ max were not significantly affected (Figures 5 and 6). All patients were found asymptomatic during the study period.

\section{DVH data}

Fourteen patients (70\%) had V20 lung dose constraint $<30 \%$; however, in $6(30 \%) \mathrm{V} 20>30 \%$ of accepted due to the nature of the patient's contours. The mean ipsilateral lung V5, V10, V20, V30, V40, and V50 were 39.5\%, 27.8\%, 22.5\%, 18.7\%, $15.0 \%$, and $1.8 \%$, respectively (Figure 7 ). Significant association between high V20 with decrease in $\mathrm{FVC}, \mathrm{FEV}_{1}$, and DLCO was observed $(P=0.01, P=0.002$, and $P=0.001$, respectively). Further, neoadjuvant chemotherapy was associated with decrease in DLCO at day $90(P=0.001)$.

\section{Discussion}

In our cohort, a significant reduction of $\mathrm{FVC}, \mathrm{FEV}_{1}$, and DLCO and an association with ipsilateral lung V20 were observed at day 90 after the completion of PMRT; however, no deterioration of $\mathrm{MMEF}_{25-75}$ and $\mathrm{VO}_{2}$ max was observed. These results are in agreement with previously published data. ${ }^{12,13}$ An equal reduction of $\mathrm{FVC}$ and $\mathrm{FEV}_{1}$ with normal $\mathrm{FEV}_{1} \%$ pred suggests an acute exudative inflammatory process in the alveolar spaces, favoring a restrictive lung injury pattern (RIP or RIF). ${ }^{14}$ Further, unaltered $\mathrm{MMEF}_{25-75}$ supports the restrictive radiation-induced lung injury in our cohort, as deterio-

Baseline FVC (L)

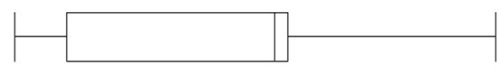

Day 30 FVC (L)

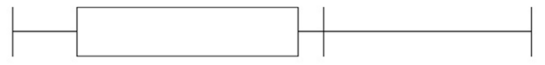

Day 90 FVC $(L)$

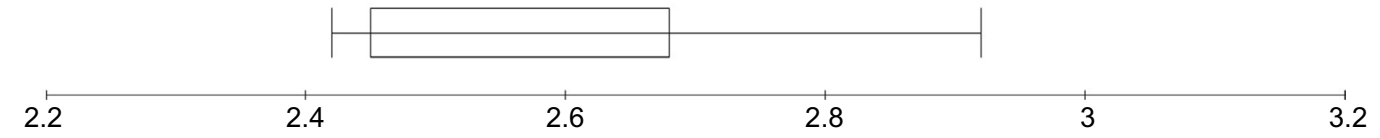

Figure 2 FVC measurements before and after treatment for breast cancer patients treated with local radiotherapy.

Abbreviation: FVC, forced vital capacity.

Baseline $\mathrm{FEV}_{1}(\mathrm{~L} / \mathrm{s})$

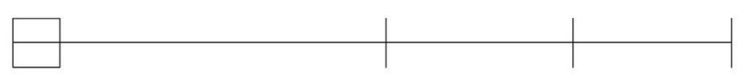

Day $30 \mathrm{FEV}_{1}(\mathrm{~L} / \mathrm{s})$

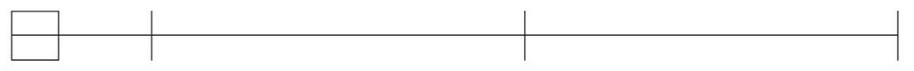

Day $90 \mathrm{FEV}_{1}(\mathrm{~L} / \mathrm{s})$

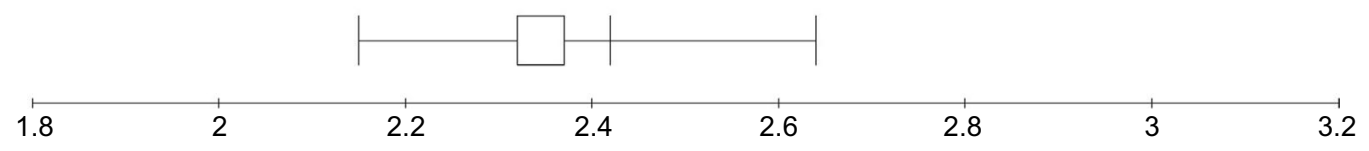

Figure 3 FEV, measurements before and after treatment for breast cancer patients treated with local radiotherapy.

Abbreviation: $\mathrm{FEV}_{1}$, forced expiratory volume in I second. 
Baseline DLCO (mmol/kPa/min)

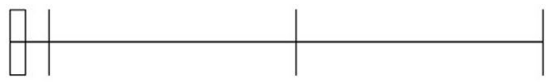

Day 30 DLCO (mmol/kPa/min)

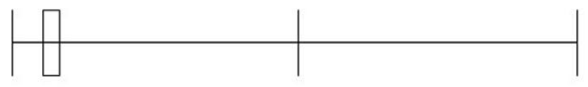

Day 90 DLCO (mmol/kPa/min)

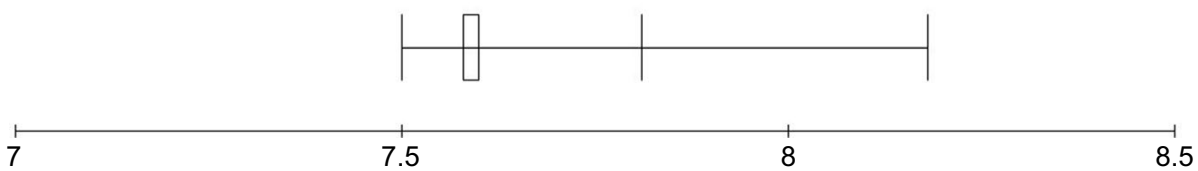

Figure 4 DLCO measurements before and after treatment for breast cancer patients treated with local radiotherapy. Abbreviation: DLCO, carbon monoxide diffusing capacity.

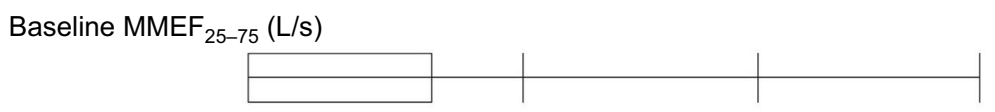

Day $30 \mathrm{MMEF}_{25-75}(\mathrm{~L} / \mathrm{s})$

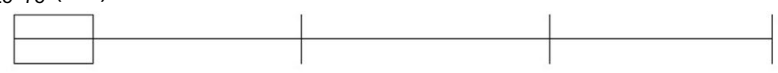

Day $90 \mathrm{MMEF}_{25-75}(\mathrm{~L} / \mathrm{s})$

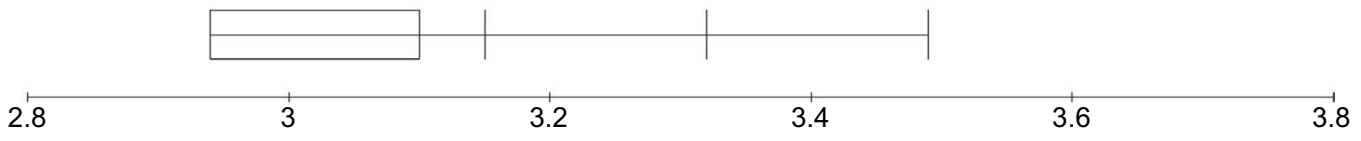

Figure $5 \mathrm{MMEF}_{25-75}$ measurements before and after treatment for breast cancer patients treated with local radiotherapy.

Abbreviation: $\mathrm{MMEF}_{25-75}$, maximum mid expiratory flow.

Baseline $\mathrm{VO}_{2} \max$

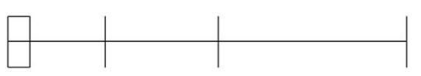

Day $30 \mathrm{VO}_{2} \max$

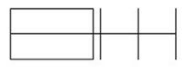

Day $90 \mathrm{VO}_{2} \max$

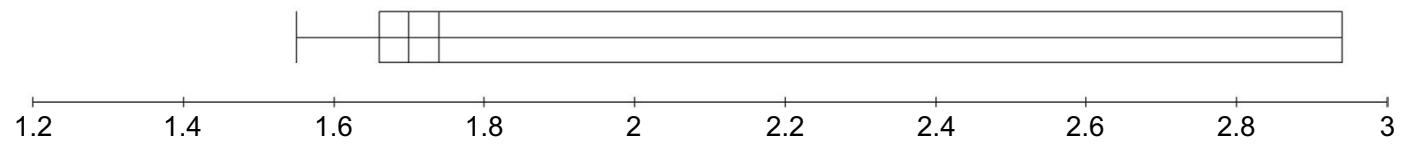

Figure $6 \mathrm{VO}_{2} \max$ measurements before and after treatments for breast cancer patients treated with local radiotherapy.

Abbreviation: $\mathrm{VO}_{2} \max$, maximum oxygen consumption.

rated $\mathrm{MMEF}_{25-75}$ is related to damage to bronchioles leading to obstructive lung disease. ${ }^{15}$ Similarly, $\mathrm{VO}_{2} \max$, which is a measure of physical fitness of an individual, was found unchanged in our cohort. Possible explanation for this could be the compensation of RILT by contralateral healthy lung. ${ }^{16}$

Although we did not aim to investigate the ability of PFTs to predict the risk of RILT, but topic is still arguable, as some studies have reported that better baseline PFTs predicted lower risk of RILT, whereas some studies did not see any correlation between PFTs and RILT. ${ }^{17,18}$ Impact of PFTs to predict the risk of RILT can be explained by the few hypotheses: 1) theoretically, individuals with better baseline PFTs have relatively higher level of cellular oxygenation, thus more radiosensitivity of alveoli and more risk of RILT; ${ }^{19} 2$ ) on the other hand, patients with poor baseline PFTs are more likely to present with symptoms prior to radiotherapy, and in individuals with severe baseline pulmonary symptoms, the RILT score is less likely to decrease by one grade, ${ }^{19,20}$ 3 ) as most of PFT data are available from lung cancer trials comprising patients who are mostly with emphysematous lungs. Since emphysema represents physiological missing lung parenchyma, theoretically one would expect less risk 


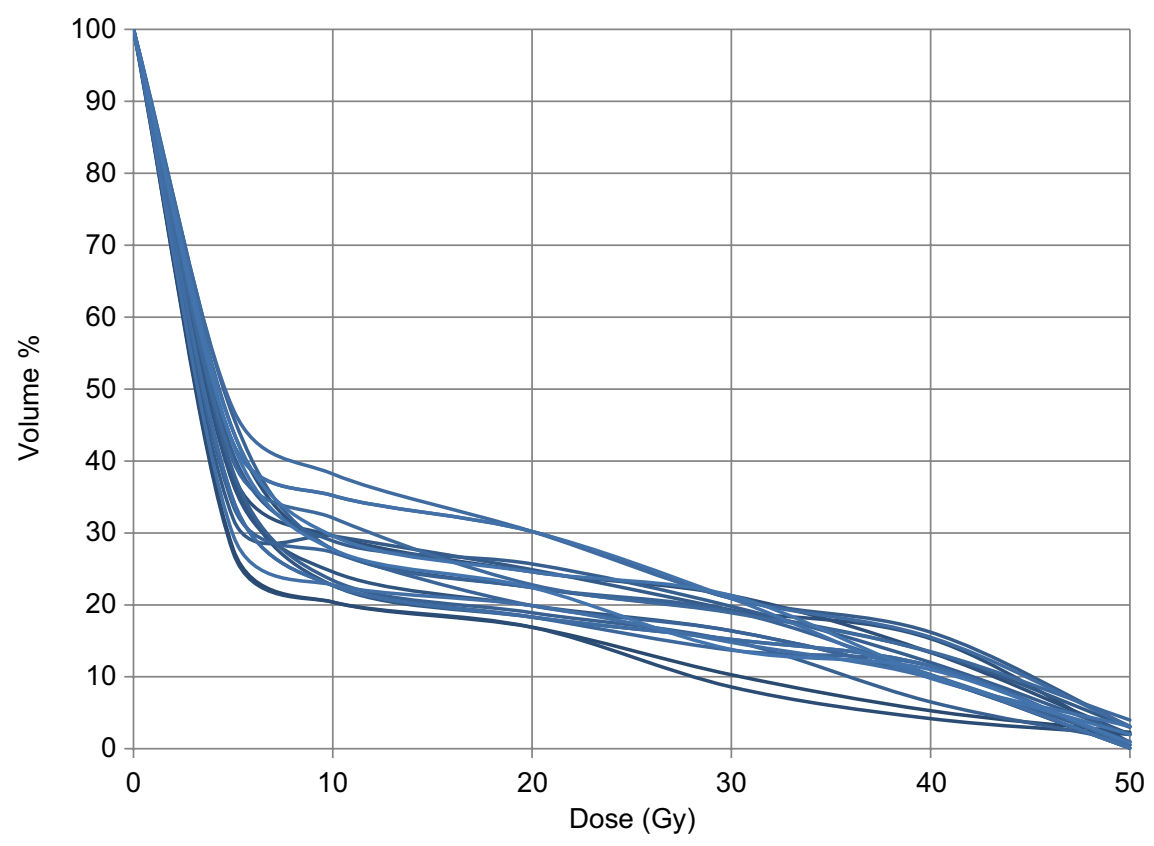

Figure 7 Cumulative lung-dose constraint DVH data. Abbreviation: DVH, dose-volume histogram.

of RILT risk; and 4) physicians' bias reduction of total dose or putting more stringent lung constraints in patients with poor baseline PFTs; ${ }^{21}$ however, further studies using the radiological data are warranted. As RILT with clinical symptoms is relatively rare (incidence $<3 \%$ ) and of mild nature especially with use of modern radiation therapy techniques, the treatment is oral steroids; therefore prevention (reducing lung volume and fraction size) is the key buttress. ${ }^{22}$ Further, treatment for patients with decrease in PFTs in the absence of clinical symptoms needs further investigation.

Limitations of the present study were 1) a relatively small sample size, 2) short follow-up duration, and 3) lack of correlation analysis between PFTs and RILT.

\section{Conclusion}

In conclusion, PFTs shall be performed in all breast cancer patients receiving PMRT for early detection of RILT as most of the patients in our cohort were asymptomatic. Studies incorporating longer duration of follow-up and large sample size are warranted to address clinical significance of PFTs in breast cancer patients receiving PMRT.

\section{Disclosure}

The authors report that no conflicts of interest in this work.

\section{References}

1. Krengli M, Sacco M, Loi G, et al. Pulmonary changes after radiotherapy for conservative treatment of breast cancer: a prospective study. Int J Radiat Oncol Biol Phys. 2008;70(5):1460-1467.
2. Fragkandrea I, Kouloulias V, Mavridis P, et al. Radiation induced pneumonitis following whole breast radiotherapy treatment in early breast cancer patients treated with breast conserving surgery: a single institution study. Hippokratia. 2013;17(3):233-228.

3. Lind PA, Marks LB, Jamieson TA, et al. Predictors for pneumonitis during locoregional radiotherapy in high-risk patients with breast carcinoma treated with high-dose chemotherapy and stem-cell rescue. Cancer. 2002;94(11):2821-2829.

4. Gong HY, Hu WG, Hu QY, Li XP, Song QB. Radiation-induced pulmonary injury accelerated pulmonary metastasis in a mouse model of breast cancer. Oncol Lett. 2015;10(6):3613-3618.

5. Toma CL, Serbescu A, Alexe M, Cervis L, Ionita D, Bogdan MA. The bronchoalveolar lavage pattern in radiation pneumonitis secondary to radiotherapy for breast cancer. Maedica (Buchar). 2010;5(4): 250-257.

6. Kimsey FC, Mendenhall NP, Ewald LM, Coons TS, Layon AJ. Is radiation treatment volume a predictor for acute or late effect on pulmonary function? A prospective study of patients treated with breast-conserving surgery and postoperative irradiation. Cancer. 1994;73(10):2549-2555.

7. Ooi GC, Kwong DL, Ho JC, et al. Pulmonary sequelae of treatment for breast cancer: a prospective study. Int J Radiat Oncol Biol Phys. 2001; 50(2):411-419.

8. Budach W, Bolke E, Kammers K, Gerber PA, Nestle-Krämling C, Matuschek C. Adjuvant radiation therapy of regional lymph nodes in breast cancer - a meta-analysis of randomized trials-an update. Radiat Oncol. 2015;10:258.

9. Lind PA, Marks LB, Hardenbergh PH, et al. Technical factors associated with radiation pneumonitis after local + - - regional radiation therapy for breast cancer. Int J Radiat Oncol Biol Phys. 2002;52(1):137-143.

10. Bjermer L, Franzen L, Littbrand B, Nilsson K, Angstrom T, Henriksson R. Effects of smoking and irradiated volume on inflammatory response in the lung of irradiated breast cancer patients evaluated with bronchoalveolar lavage. Cancer Res. 1990;50:2027-2030.

11. Bentzen SM, Skoczylas JZ, Overgaard M, Overgaard J. Radiotherapyrelated lung fibrosis enhanced by tamoxifen. J Natl Cancer Inst. 1996; 88(13):918-922.

12. Spyropoulou D, Leotsinidis M, Tsiamita M, Spiropoulos K, Kardamakis D. Pulmonary function testing in women with breast cancer treated with radiotherapy and chemotherapy. In Vivo. 2009;23(5):867-871. 
13. Fleckenstein K, Gauter-Fleckenstein B, Jackson IL, Rabbani Z, Anscher M, Vujaskovic Z. Using biological markers to predict risk of radiation injury. Semin Radiat Oncol. 2007;17(2):89-98.

14. Schytte T, Bentzen SM, Brink C, Hansen O. Changes in pulmonary function after definitive radiotherapy for NSCLC. Radiother Oncol. 2015;117:23-28.

15. Quanjer PH, Weiner DJ, Pretto JJ, Brazzale DJ, Boros PW. Measurement of FEF25-75\% and FEF75\% does not contribute to clinical decision making. Eur Respir J. 2014;43(4):1051-1058.

16. Casla S, Lopez-Tarruella S, Jerez Y, et al. Supervised physical exercise improves VO2max, quality of life, and health in early stage breast cancer patients: a randomized controlled trial. Breast Cancer Res Treat. 2015;153(2):371-382.

17. Robnett TJ, Machtay M, Vines EF, McKenna MG, Algazy KM, McKenna WG. Factors predicting severe radiation pneumonitis in patients receiving definitive chemoradiation for lung cancer. Int J Radiat Oncol Biol Phys. 2000;48(1):89-94.
18. Dehing-Oberije C, De Ruysscher D, van Baardwijk A, Yu S, Rao B, Lambin P. The importance of patient characteristics for the prediction of radiation-induced lung toxicity. Radiother Oncol. 2009;91(3): $421-426$.

19. Wang J, Cao J, Yuan S, et al. Poor baseline pulmonary function may not increase the risk of radiation-induced lung toxicity. Int J Radiat Oncol Biol Phys. 2013;85(3):798-804.

20. Yuan ST, Frey KA, Gross MD, et al. Changes in global function and regional ventilation and perfusion on SPECT during the course of radiotherapy in patients with non-small-cell lung cancer. Int $J$ Radiat Oncol Biol Phys. 2012;82:e631-e638.

21. Hernando ML, Marks LB, Bentel GC, et al. Radiation-induced pulmonary toxicity: a dose-volume histogram analysis in 201 patients with lung cancer. Int J Radiat Oncol Biol Phys. 2001;51(3):650-659.

22. Zhang XJ, Sun JG, Sun J, et al. Prediction of radiation pneumonitis in lung cancer patients: a systematic review. J Cancer Res Clin Oncol. 2012; 138(12):2103-2116.
Breast Cancer - Targets and Therapy

\section{Publish your work in this journal}

Breast Cancer - Targets and Therapy is an international, peerreviewed open access journal focusing on breast cancer research, identification of therapeutic targets and the optimal use of preventative and integrated treatment interventions to achieve improved outcomes, enhanced survival and quality of life for the cancer patient.

\section{Dovepress}

The manuscript management system is completely online and includes a very quick and fair peer-review system, which is all easy to use. Visit http://www.dovepress.com/testimonials.php to read real quotes from published authors. 